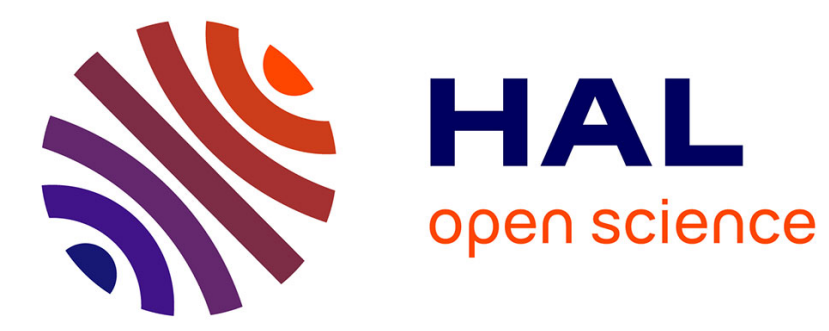

\title{
Electrooptic beam deflection with latex
}

F. Bloisi, P. Cavaliere, S. Martellucci, P. Mormile, G. Pierattini, J. Quartieri, L. Vicari

\section{To cite this version:}

F. Bloisi, P. Cavaliere, S. Martellucci, P. Mormile, G. Pierattini, et al.. Electrooptic beam deflection with latex. Revue de Physique Appliquée, 1988, 23 (1), pp.97-99. 10.1051/rphysap:0198800230109700 . jpa-00245752

HAL Id: jpa-00245752

https://hal.science/jpa-00245752

Submitted on 1 Jan 1988

HAL is a multi-disciplinary open access archive for the deposit and dissemination of scientific research documents, whether they are published or not. The documents may come from teaching and research institutions in France or abroad, or from public or private research centers.
L'archive ouverte pluridisciplinaire HAL, est destinée au dépôt et à la diffusion de documents scientifiques de niveau recherche, publiés ou non, émanant des établissements d'enseignement et de recherche français ou étrangers, des laboratoires publics ou privés. 


\title{
Electrooptic beam deflection with latex
}

\author{
F. Bloisi $\left({ }^{1}\right)$, P. Cavaliere $\left({ }^{2}\right)$, S. Martellucci $\left({ }^{3}\right)$, P. Mormile $\left({ }^{4}\right)$, G. Pierattini $\left({ }^{4}\right)$, J. Quartieri \\ $\left({ }^{3}\right)$ and L. Vicari $\left({ }^{1}\right)$ \\ (') Dipartimento di Fisica Nucleare, Struttura della Materia e Fisica Applicata, Università di Napoli, Napoli, \\ Italy \\ $\left({ }^{2}\right)$ Istituto di Fisica, Università di Palermo, Palermo, Italy \\ ( $\left.{ }^{3}\right)$ Dipartimento di Ingegneria Meccanica, Università Tor Vergata, Roma, Italy \\ $\left({ }^{4}\right)$ Istituto di Cibernetica, C.N.R., Arco Felice, Napoli, Italy
}

(Reçu le 20 mars 1987, révisé le 10 septembre 1987, accepté le 15 septembre 1987)

\begin{abstract}
Résumé. - Nous proposons l'utilisation de suspensions aqueuses de latex dans un dispositif électrooptique. Un calcul théorique montre que le coefficient statique de non-linéarité devrait être 200 fois plus élevé que le coefficient optique. Nous proposons d'utiliser cette suspension dans un déflecteur optique et nous donnons une expression de l'angle de déflection en fonction des paramètres du milieu.
\end{abstract}

\begin{abstract}
The use of latex in electrooptic devices is proposed. The static «non linearity " coefficient is shown to be approximatively 200 times the optical one. The theory of a beam deflector is developed and an explicit expression is given for the deflection angle versus the physical parameters of the sample.
\end{abstract}

\section{Introduction.}

Artificial Kerr mediums appears to be very interesting owing to their very high non linearity coefficient. Since the first studies on vapors and aerosols $[1,2]$ attention has been devoted particularly to suspensions of submicron particles in a liquid. Four wave mixing [3] and self focusing [4] experiments have been reported for polystyrene latex [5] while accurate studies of the dependence of the non linearity coefficient versus the concentration and the particle radius have been carried out [6]. Less attention, to our knowledge, has been devoted to the use of such material in electrooptic devices. In fact the refractive index of artificial Kerr mediums is affected by spatial variations of $|E|^{2}$, as in the usual Kerr mediums, but temporal variations of the electric field can have some effect only at low frequency. On the other hand, as it is quite difficult to obtain strong electric intensity spatial gradients, they are usually obtained by means of light or interference gratings. Nevertheless, as will be shown in this paper, the strong non linearity of aqueous suspensions of particles is further enhanced under static or quasi static conditions owing to the polar characteristics of water molecules. In fact under these conditions the non linearity depends not only on the relative refractive index but also on the electric permittivity of the substances involved. In this paper we discuss the deviation of a probe beam passing through a cylindrical cell filled with a latex.

\section{Principle.}

It is well known [7] that the force exerted by an electric field $\mathbf{E}$ on a dielectric sphere having relative permittivity $\varepsilon_{a}$ and radius $a$ embedded in a dielectric medium having relative permittivity $\varepsilon_{b}$ is

$$
F=-\nabla \Phi
$$

with

$$
\begin{aligned}
& \Phi=-(\alpha / 2) E^{2} \\
& \alpha=4 \pi \varepsilon_{0} \varepsilon_{b} \frac{\varepsilon_{a} / \varepsilon_{b}-1}{\varepsilon_{a} / \varepsilon_{b}+2} a^{3} .
\end{aligned}
$$

The osmotic pressure is

$$
p=-N \Phi
$$

where $N$ is the number of particles per unit volume. If $p_{0}$ is the pressure for zero electric field, then the pressure variation due to the field is

$$
\delta p=p-p_{0}=-N \Phi=(N \alpha / 2) E^{2} .
$$


Let $n_{a}$ be the refractive index of the particles and $n_{b}$ that of the surrounding medium. For the refractive index $n$ we have

$$
n=n_{0}+\delta N\left(n_{a}-n_{b}\right) 4 \pi a^{3} / 3
$$

with

$$
n_{0}=n_{b}+N_{0}\left(n_{a}-n_{b}\right) 4 \pi a^{3} / 3
$$

where $N_{0}$ is the number of particles per unit volume for zero electric field, and $\delta N=N-N_{0}$ is the variation of the number of particles due to the field.

Let us assume the number of particles to be high enough that the electric field affects only slightly their distribution $\left(\delta N \ll N, N \approx N_{0}\right)$. We have

$$
n=n_{0}+K \delta p\left(n_{a}-n_{b}\right) 4 \pi a^{3} / 3
$$

where $K=\partial N / \partial p$ is the osmotic compressibility. Finally, taking into account equation (4), with $N \approx N_{0}$, and equation (2)

$$
n=n_{0}+n_{2} E^{2}
$$

where

$$
\begin{aligned}
n_{2}=\varepsilon_{0} \varepsilon_{b} \frac{1-\varepsilon_{a} / \varepsilon_{b}}{2+\varepsilon_{a} / \varepsilon_{b}}\left(n_{b}-n_{a}\right) & \times \\
& \times N_{0} K 8 \pi^{2} a^{6} / 3 .
\end{aligned}
$$

Since, for non interacting particles, $K=(k T)^{-1}$, where $k$ is the Boltzmann constant and $T$ the absolute temperature, we have

$$
\begin{aligned}
n_{2}=\varepsilon_{0} \varepsilon_{b} \frac{1-\varepsilon_{a} / \varepsilon_{b}}{2+\varepsilon_{a} / \varepsilon_{b}}\left(n_{b}-\right. & \left.n_{a}\right) \times \\
& \times N_{0} 8 \pi^{2} a^{6} / 3 k T .
\end{aligned}
$$

\section{Beam deflection.}

In figure 1 we show a drawing of the device. The probe beam trajectory may be derived from the equation for the ray propagation in non-homogeneous medium [8].

$$
\frac{\mathrm{d}}{\mathrm{d} s}\left(n \frac{\mathrm{d} \mathbf{r}}{\mathrm{d} s}\right)=\nabla n \text {. }
$$

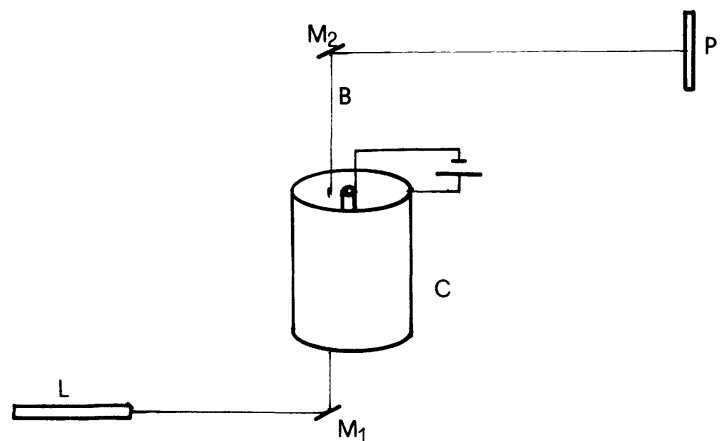

Fig. 1. - Deflector scheme ; C : cell ; L : laser ; B : beam ; $\mathbf{M}_{1}, \mathrm{M}_{2}$ : mirrors; $\mathrm{P}$ : position sensor.
For small beam deflection and owing to the orthogonality between the beam trajectory and $n$ the expression (10) may be reduced to [9]

$$
\frac{\mathrm{d}^{2} r}{\mathrm{~d} z^{2}}=\left.\frac{1}{n\left(r_{0}\right)} \frac{\mathrm{d} n}{\mathrm{~d} r}\right|_{r_{0}}
$$

where $r_{0}$ is the beam distance from the symmetry axis of the device, assumed to be the $z$ axis. For small deflection angles $\theta(\operatorname{tg} \theta \approx \theta)$, integrating we get

$$
\theta=\left.\frac{1}{n\left(r_{0}\right)} \frac{\mathrm{d} n}{\mathrm{~d} r}\right|_{r_{0}} L
$$

where $L$ is the cell length. Since

$$
E^{2}=r_{0}^{-2} V^{2} / \ln ^{2}\left(R_{\mathrm{i}} / R_{\mathrm{c}}\right)
$$

where $V$ is the applied voltage and $R_{\mathrm{i}}$ and $R_{\mathrm{c}}$ are respectively the internal and external radii of the cell, from equations (7), (9), (12) and (13) we have

$$
\theta=-\frac{2 L}{r_{0}+r_{0}^{3} n_{0} \ln ^{2}\left(R_{\mathrm{i}} / R_{\mathrm{c}}\right) /\left(V^{2} n_{2}\right)}
$$

\section{Discussion.}

The non linearity coefficient for an artificial Kerr medium with light induced electric gradient [6] can be obtained from equation (9) with $\varepsilon_{a}=n_{a}^{2}$ and $\varepsilon_{b}=n_{b}^{2}$ :

$$
\begin{aligned}
n_{20}=\varepsilon_{0} n_{b}^{3} \frac{\left(1-n_{a} / n_{b}\right)\left(1-n_{a}^{2} / n_{b}^{2}\right)}{2+n_{a}^{2} / n_{b}^{2}} & \times \\
\times & N_{0} 8 \pi^{2} a^{6} / 3 k T
\end{aligned}
$$

therefore for the ratio $n_{2} / n_{20}$ we have

$$
\frac{n_{2}}{n_{20}}=\frac{\varepsilon_{b}}{n_{b}^{2}} \frac{2+n_{a}^{2} / n_{b}^{2}}{1-n_{a}^{2} / n_{b}^{2}} \frac{1-\varepsilon_{a} / \varepsilon_{b}}{2+\varepsilon_{a} / \varepsilon_{b}}
$$

that, for a polystyrene latex with $\varepsilon_{b}=80.3$, $\varepsilon_{a}=2.3, n_{b}=1.33, n_{a}=1.59$ gives $n_{2} / n_{20}=-174$. The non linearity coefficient in static conditions is hence two orders of magnitude higher than the optical one which by itself is $10^{5}$ times that of $\mathrm{CS}_{2}$ (for $a=0.234 \mu \mathrm{m} \mathrm{[3]).} \mathrm{This} \mathrm{means} \mathrm{that} \mathrm{appreci-}$ able beam deflections may be obtained with relatively small applied voltages. Further we observe that the ratio $n_{2} / n_{20}$ is negative because, while in optical arrangements the latex particles are pushed toward the zones of higher electrical intensity, they move toward the external side of the cell in the device here presented. As a consequence the beam also is deflected away from the cell axis and not toward it like it would be if the electrical gradient were light induced.

In figure 2 we show an example of beam deflection versus the applied voltage for $L=10 \mathrm{~mm}$, 


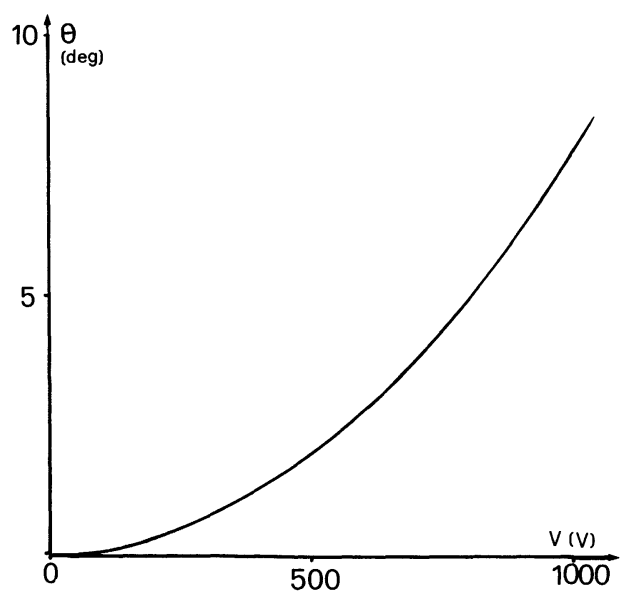

Fig. 2. - Deflection angle $\theta$ (deg) versus voltage $V$ (V).

$R_{\mathrm{i}}=1 \mathrm{~mm}, R_{\mathrm{c}}=10 \mathrm{~mm}, a=0.1 \mu \mathrm{m}, T=300 \mathrm{~K}$, $N_{0}=66.3 \times 10^{16} \mathrm{~m}^{-3}, r_{0}=2 \mathrm{~mm}$.

\section{Conclusions.}

The use of artificial Kerr-like mediums in electrooptic devices has been discussed. The dependence of refractive index on the square electric intensity has been computed and shown to be approximatively 170 times higher than the optical non linearity coefficient. The theory of a simple beam deflector has been developed and it has been shown that an appreciable beam deflection may be achieved using a polystyrene latex and applying relatively small voltages. An explicit expression has been obtained for the deflection angle, in terms of the physical and geometrical parameters of the system. The deflection angle carries information about the concentration and radius of suspended particles and hence may be used for their determination.

The authors thank the referees for their comments and acknowledge the request of one of them for an experimental support. Nevertheless their laboratory is now involved in other programs: hence this experiment may require some time to be performed. The theoretical work developed here may suggest some experiment to other people.

The authors wish to thank the fruitful assistance of Mr. A. Finizio and Mr. E. Casale.

\section{References}

[1] Palmer, A. J., Opt. Commun. 30 (1979) 104.

[2] Palmer, A. J., Opt. Lett. 5 (1980) 54.

[3] Smith, P. W., Ashkin, A. and Tomlinson, W. J., Opt. Lett. 6 (1981) 284.

[4] Ashion, A., Dziedzic, J. M. and Smith, P. W., Opt. Lett. 7 (1982) 276.

[5] Dow Chemical Company uniform polystyrene latex particles.
[6] Smith, P. W., Maloney, P. J. and Ashkin, A., Opt. Lett. 7 (1982) 347.

[7] JACKSON, J. D., Classical electrodynamics (J. Wiley \& Sons, New York, London, Sydney) 1966.

[8] Born, M. and Wolf, E., Principle of Optics (Pergamon, New York) 1965.

[9] Yun, S. I., OH, K. D., RYU, K. S., KIM, C. G., Park, H. L., SeO, H. J., Kum, C., Appl. Phys. B 40 (1986) 95. 